\title{
Práticas artísticas contra o esquecimento dos conflitos quotidianos na América Latina: Berna Reale, Teresa Margolles e Oscar Muñoz
}

Susana Rocha ${ }^{1}$

Faculdade de Belas-Artes da Universidade de Lisboa (FBAUL), Portugal

\begin{abstract}
Desmistificando a visão da arte latino-americana como uma arte menor, dependente de apropriaçóes e reformulaçóes de conceitos vindos de universos a si estranhos, este texto analisa como os contextos sociais de um número significativo de paises da América Latina, e a capacidade interventiva da arte junto da sociedade, têm sido marcantes para a afirmação definitiva de uma legitima autonomia que recusa qualquer dependência do eixo artístico europeu/norte-americano. Partindo sobretudo dos textos do teórico Geardo Mosquera, e abordando as obras de três artistas contemporâneos latino-americanos: Berna Reale (Brasil), Teresa Margolles (México) e Oscar Muñoz (Colômbia), evidencia-se o modo como, apesar de socialmente envolvida com o seu contexto, a arte criada a partir da América Latina, se afirmada com um carácter global que ultrapassa em muito qualquer noção de fronteira, participando de um diálogo internacional. Propóe-se que, caso alguma característica diferencie a arte produzida na América Latina, esta seja a vontade de uma arte baseada numa consciência de um não condicionamento às estruturas estabelecidas.

Palavras-chave: práticas artísticas, denúncia, Berna Reale, Teresa Margolles, Oscar Muñoz
\end{abstract}

\section{DA ADVERSIDADE VIVEMos! ${ }^{2}$}

Cada época histórica e cada espaço geográfico, com o seu contexto social e político, despertam nos artistas reacções e estímulos que são frequentemente canalizados para a produção artística. É assim natural que as suas obras se tornem relatos e evidências dos problemas de um lugar e de uma época, e simultaneamente o seu legado.

1 Centro de Investigação e Estudos em Belas Artes (CIEBA). Bolseira da Fundação para a Ciência e Tecnologia (FCT), Portugal. Contacto: susanavrocha@gmail.com.

2 Lema da Nova Objectividade, proposto por Hélio Oiticica no texto "Esquema Geral da Nova Objectividade". 
A América Latina (se um tão alargado conceito resiste à disparidade das suas realidades) é um exemplo claro de como a prática artística se impulsiona pela necessidade de autonomia, podendo problematizar questões nacionais, históricas, sociais, políticas ou simplesmente geográficas, sem produzir uma arte regional, e sem limitar o impacto e a relevância das obras a um contexto menor.

Porém, só recentemente as práticas artísticas para lá do eixo europeu/norte-americano, começaram a receber o seu legitimo reconhecimento, sem as tradicionais conotações de exotismo, folclore ou tropicalidade, ou sem serem caracterizadas como uma degeneração de uma história da arte oficial - ou seja ocidental.

Assim sendo, recuemos um pouco para relembrar três momentos relevantes.

Em 1928, Oswald de Andrade cunhava o termo "antropofagia", ${ }^{3}$ não tanto como um conceito teórico, mas antes como uma expressão manifesto. Tornando-o uma metáfora, pretendia representar numa só palavra a condição ambígua do modernismo brasileiro, que se apropriava das ideias fortes do modernismo europeu, mas que simultaneamente pretendia ser diferente deste. Este tipo de abordagem paradoxal, extensivamente usada na América Latina no inicio do século, ou nas primeiras décadas do modernismo, revelou-se um acto de envolvimento social, e de resistência pós-colonial, que na sua relação difícil com os países europeus, os mantinha ainda como referência. Poder-se-ia considerar que esta questão estaria há muito ultrapassada, porém, na XXIV Bienal de São Paulo, em 1998, com curadoria de Paulo Herkwnhoff, a questão da "antropofagia" seria central, motivando uma discussão sobre o seu carácter rizomático que subsiste até hoje.

Décadas após o "Manifesto Antropófago”, para o brasileiro Hélio Oiticica, a possibilidade do pós-modernismo se desenvolver para lá do seu centro de origem tornou-se um foco central de pesquisa e de proposta educativa para uma sociedade. Chamando-lhe "Nova Objectividade", e designando-o como um estado da arte ao invés de um movimento, Oiticica definiu seis características principais para esta arte de vanguarda: "1: vontade construtiva geral; 2 : tendência para o objecto ao ser negado e superado o quadro do cavalete; 3: participação do espectador (corporal, táctil, visual, semântica etc.); 4: abordagem e tomada de posição em relação a problemas políticos, sociais e éticos; 5: tendência para proposições colectivas e consequente abolição dos "ismos" característicos da primeira metade do século na arte de hoje (...); 6: ressurgimento e novas formulações do conceito de antiarte.” (Oiticica, 1967).

A proposta de Hélio Oiticica de uma arte para além do mero conformismo limitado presente num objecto (que necessariamente estimula uma reacção, habitualmente passiva), abriu portas à participação do espectador. E a incorporação da componente de participação tornou-se crucial para muitos artistas que trabalhavam na América Latina, nas décadas de 1960 e 1970, como forma de resistir às ditaduras que permearam os seus diversos países, e como forma de escapar definitivamente ao ascendente do eixo estético-cultural europeu/norte-americano. $\mathrm{Na}$

3 O termo "antropofagia” é usado por Oswald de Andrade no "Manifesto Antropófago" tornado público no No1 da "Revista de Antropofagia” (1928), publicada em São Paulo. O mesmo inicia-se, ao jeito modernista, do seguinte modo: "Só a Antropofagia nos une. Socialmente. Economicamente. Filosoficamente. / Única lei do mundo. Expressão mascarada de todos os individualismos, de todos os coletivismos. De todas as religiões. De todos os tratados de paz. / Tupi, or not tupi that is the question." 
verdade, no contexto dos países da América do Sul, podemos observar a importância da arte participativa, bem como da performance em espaço público, tanto ou mais nos dias de hoje.

Gerardo Mosquera voltaria a problematizar a autonomia da arte latino-americana com o texto "Contra a Arte Latino-americana". Referindo o conceito de "antropofagia" de Oswald de Andrade, bem como o termo "transculturação" cunhado por Fernando Ortiz em 1948, que ressalva o papel activo do indivíduo no intercâmbio cultural implícito em todas as aculturações, Mosquera chamaria a atenção para dois atritos causados por dinâmicas sintetizadoras presentes em contextos onde um centro cultural parece ter um ascendente sobre outro (nomeadamente Europa/América do Norte vs América Latina). O primeiro seria uma falsa noção de fusão equitativa e harmónica entre a cultura dominante e a cultura subalterna esquecendo as flagrantes desigualdades e contradições; o segundo seria o erro em ver estes processos como uma simples fórmula matemática, baseada na soma ou divisão de elementos culturais, esquecendo os conceitos não assimiláveis. (Mosquera, 2010)

Identificando a consumação destes dois erros nas dinâmicas modernistas e até pós-modernistas, o teórico e curador cubano, defende um pluralismo neutral, um "multiculturalismo" na arte onde as relações de poder não se orientem de norte para sul, referindo como os circuitos artísticos e culturais estabelecidos, tanto nos mercados na arte como nas dinâmicas presentes nas instituições artísticas, com os seus próprios interesses, têm dificultado e limitado a internacionalização da prática artística contemporânea oriunda das diversas partes do mundo, descartando-a com base no lugar em que são produzidas. (Mosquera, 2010)

Contudo, ou apesar disso, ressalva que, actualmente, "em vez de apropriar e atribuir nova função de modo critico à cultura internacional imposta, transformando-a em beneficio próprio, os artistas [fora do eixo] estão a construir activamente uma metacultura em primeira estância, sem complexos, a partir dos seus próprios imaginários e perspectivas. (...) Em geral, a obra de muitos artistas de hoje, mais que nomear, descrever, analisar, expressar ou construir contextos, é feita dos seus contextos - pessoais, históricos, culturais e sociais - em termos internacionais." (Mosquera, 2010: 15)

Deste modo, antes de retomarmos as considerações de Mosquera, pensemos sobre as práticas artísticas exemplares de três artistas: Berna Reale (brasileira), Teresa Margolles (mexicana) e Óscar Muñoz (colombiano), onde os conflitos quotidianos da América Latina não só estão presentes, como são o indutor da criação artística, obrigando-nos a considerar as suas obras num contexto global, mesmo partindo dos seus contextos pessoais - tal como Mosquera defendeu.

\section{Berna Reale}

Não podendo ser considerada uma jovem artista, é com surpresa que em 2012, o público brasileiro descobre o trabalho de Berna Reale (1965, Belém - PA, Brasil). Até então sem projecção considerável, é aquando da sua vitória do Prémio Pipa, que a obra da artista acende o interesse da crítica, e disperta a curiosidade do universo artistico brasileiro. Usando a performance, o vídeo e a fotografia como médiuns, Berna Reale magnetizou atenções com a capacidade de acutilância das suas obras, que de forma consagrada foram exibidas no MAR (Museu de Arte do Rio), em Setembro de 2013. A exposição "Vazio de Nós", reflexão sobre a vulnerabilidade 
humana, apresentou cinco videos de performances realizadas pela artísta: "Limite Zero" (2012), "Palomo" (2012), "Ordinário"(2013), "Soledade" (2013) e "Americano" (2013). (Rocha, 2014: 23). Em 2015, alguns destes videos seriam apresentados no Pavilhão Brasileiro da Bienal de Veneza, expondo Berna Reale à critica internacional.

O centro nevrálgico do trabalho de Reale é, como a própria aponta, a violência calada cometida sobretudo em frágeis sectores do tecido social. "A violência silenciosa ou a que é observada em silêncio, sem dúvida é a que mais me angustia. Silenciosa no sentido mais amplo possível, silenciosa no que diz respeito à tortura, aquela cometida entre paredes, a silenciosa por parte dos espectadores e silenciosa por meio do poder." (Reale apud Fonseca 2013)

Tomemos como ponto de partida a performance "Ordinário", onde a artista transporta, num carro de mão, esqueletos abandonados de vítimas de homicidio não identificadas. Trabalhando profissionalmente como perita criminal, Berna Reale acede a um conjunto de ossadas de cerca de 40 índividuos, que transporta, atravessando o violento bairro de Jurunas (na área metropolitana de Belém do Pará). Estes restos mortais sem identificação, frequentemente encontrados por agentes policiais em cemitérios clandestinos, são produto da elevada taxa de homicídios no Brasil.

Berna Reale, vestida de negro, passeia os ossos, sob o olhar da população, eventualmente dos perpetradores de crimes que conduziram à morte do que outrora foram habitantes locais. No vídeo não se observam reacções assinaláveis: não há choque, comoção, surpresa, ou incredulidade. E assim a artista conduz-nos a uma reflexão que nos faz crer que mesmo depois da morte, a última indignidade é o esquecimento.

Tocando questões sociais, Reale faz uso de provocações, e dinâmicas de confronto, que por vezes instrumentalizam o choque, como forma de comunicação com o público. Perante a passividade de uma sociedade que convive com a criminalidade como parte do dia comum, a capacidade de denúncia da artista é desafiada, levando-a a criar momentos de intensidade física e emocional extrema, como modo último de intervenção social. É o que acontece na performance "Limite Zero".

Desde os anos 70 que a arte enquanto fenómeno onde o público pode adoptar uma postura participativa tem sido uma questão a considerar, como vimos a propósito do pós-modernismo e de Hélio Oiticica. Esta participação ou colaboração procura tanto uma aproximação dos públicos, como um envolvimento social dos mesmos, e a performance surgiu como uma das expressões mais estimuladoras desta interacção em potência. $O$ público das performances de Berna, torna-se participativo pelo testemunho da analogia a um crime, no qual decidiu não intervir: torna-se de certo modo, a testemunha silenciosa, e portanto envolvida no crime/performance, materializando dessa forma a suprema aflição da artista - a violência perante a qual todos calam.

Na performance "Limite Zero", os pés e mãos de Reale são amarrados a uma barra de ferro, como se de um animal morto se tratasse. Retirando-a de um camião refrigerado, indivíduos que se assemelham a enfermeiros ou a talhantes, passeiam-na pela cidade, onde o público pára para observar a sua passagem. As reacções são uma vez mais passivas; em alguns casos, quase nulas. Como se uma razão justa estivesse subjacente ao tratamento extremado de um ser humano. Como se a imagem que vêem pudesse carregar consigo alguma justificação (Rocha, 2014). 
Berna Reale joga com estratégias visuais, psicológicas e emocionais, criando uma estética de agressão, ameaça, fracasso, risco e morte, que mais não é que um grito contra o silêncio que oprime a possibilidade de intervenção, não só no domínio da violência social, mas também em contexto privado ou doméstico.

\section{Teresa Margolles}

À semelhança de Berna Real, também Teresa Margolles é, para além de artista plástica, especialista forense. O fascínio pela morte não é coisa rara ou invulgar no contexto das artes plásticas, sobretudo num país cujas tradições e cultura em muito se relacionam com a homenagem aos mortos. Porém, esta condição profissional, que tanto Margolles como Reale apresentam, permite um acesso invulgar a factos e artefactos.

Ainda que profundamente políticos, ou sociais (se preferirmos), os universos de interesse de Margolles podem ser resumidos ao que a própria designou de "a vida dos cadáveres" (Margolles apud Görner e Kittelman 2004: 41). Neste contexto, Margolles explora as relações de poder, a injustiça e as hierarquias sociais que mesmo depois da morte se mantêm e permeiam o tratamento dos mortos.

As exposições "Muerte sin Fin” no Museum für Moderne Kunst em Frankfurt (2004) e "Sem Título" na Biennal Liverpool (Tate Liverpool, 2006), apresentaram Margolles a uma atenção crítica mais vasta, testando as reacções do público à estética das suas obras, que ganham credibilidade pela sua imersão no contexto médico-legal da cidade do México.

Usando uma dinâmica de denúncia e confronto, que Margolles torna mais conceptuais que visuais, a artista mexicana faz uso, nas suas obras, de materiais fisiológicos e de componentes orgânicas no corpo, criando junto do público reacções ambíguas de repulsa e compaixão, obrigando-o a abandonar qualquer postura clínica perante a morte. Há, nas obras de Margolles, uma tentativa de consciencialização da realidade concreta do morto, que bloqueia ao observador qualquer tentativa de procura de uma poética para a morte, ainda que Margolles faça uso de uma abordagem por vezes subtil e subtil e simbólica.

No trabalho da artista, não poucas vezes, o que importa não é o que está visível mas o que nos é contado; é o fracasso humano que está escondido em cada obra, e que nos atraiçoa, apanhando-nos de surpresa.

Tomemos em consideração a obra "Vaporización" (2001) e "Entierro" (1999). Em "Vaporización" deparamo-nos com uma sala preenchida por vapor de água, oriundo de dois vaporizadores. A água vaporizada foi previamente usada na limpeza de cadáveres (resultado de crimes violentos, dados em contexto de crime organizado, tráfico, exploração sexual...), e posteriormente desinfectada para uso da artista. Contudo, ao tomar consciência do uso anterior da água, é inevitável a sensação de contaminação que assombra o público.

Esta obra de Margolles, não só remete para a última lavagem do corpo morto, pré-enterro, como para o lento processo de desaparecimento do cadáver. Simultaneamente é quebrado o tabu da separação entre vida e morte, uma vez que a "morte" se infiltra nos nossos pulmões, 
na nossa respiração, na nossa pele, através da neblina que nos circunda, e que cria uma cortina densa entre o espaço em que nos encontramos e a vida realmente vivida fora do perímetro desta sala. Dentro dela, apenas deambulamos, imersos, como num limbo, onde a dificuldade em entrevermos qualquer outra pessoa é um obstáculo presente.

Em "Entierro", também a morte e a injustiça social são a ignição do pensamento e necessidade de denúncia de Margolles. A obra apresenta-se de forma discreta, e é quase difícil prestar-lhe atenção. Apenas notamos um bloco de cimento, um tijolo, um aparente excedente de materiais de construção. Porém, quando tomamos conhecimento do que este bloco encerra torna-se subitamente doloroso e perturbador abandoná-lo.

Apesar de nas obras de Teresa Margolles a realidade da morte estar sempre presente, na maioria o corpo concreto é uma realidade periférica. Em "Entierro" isso não acontece. Dentro do bloco de cimento, encontra-se o corpo de um nado morto: uma criança formada, nascida, mas nunca viva fora do contexto uterino.

No México, nados mortos são considerados "desperdícios" médicos; e como tal não têm assegurado um funeral e um enterro, no caso de incapacidade económica dos progenitores. Perante a incapacidade da mãe em custear as despesas do enterro, Margolles cria uma tumba sólida, que encerra o corpo da criança. É uma tumba pequena, tosca, transportável mas definitiva, que simboliza o carregar permanente do luto pela perda de um filho. Não é algo que possa ser destruído, mas algo que se leva por todos os lugares.

Teresa Margolles obriga-nos a olhar e recordar o que não querermos ver e o que queremos esquecer. Através do uso da morte enquanto conceito e enquanto realidade concreta, tenta conseguir o que em vida não se revelou possível: um despertar para as tragédias sociais.

O trabalho de Margolles coloca os criminosos em julgamento permanente ao apresentar os corpos das vítimas na mesa da sociedade. Opõe-se à indiferença geral em relação aos crimes cometidos aos outros, numa outra sociedade, do outro lado do atlântico ou na televisão global, e lembra-nos constantemente que um mexicano que foi morto podia ser qualquer um de nós. (Sierra in Görner e Kittelman 2004: 214)

\section{Oscar Muñoz}

O contexto social e político da Colômbia tem sido marcado por uma luta entre aparências, representações e percepções da realidade, num ambiente violento de corrupção política, tráfico e criminalidade. Durante mais de 30 anos, Oscar Muñoz tem usado o carácter factual e identitário da fotografia e a impermanência do desenho, para criar alegorias ou metáforas, muitas vezes alusivas à Guerra Civil Colombiana (anos 60) e a outros problemas sociais da América Latina, de forma subtil, delicada mas incisiva.

$\mathrm{Na}$ continuidade das questões abordadas, tanto na obra de Berna Reale como de Teresa Margolles, vemos em Muñoz uma preocupação com a necessidade de não esquecer. Optando por estratégias poéticas e profundamente simbólicas, o confronto que Muñoz cria com o publico pode não ser tão presente quanto o das performances de Reale, nem tão inusitado quanto as 
obras de Margolles, mas é seguramente enriquecedor enquanto exploração visual que traduz a efemeridade humana e o sentimento de luto, denunciando as perdas humanas que resultam de momentos críticos da história da Colômbia.

Inegavelmente o facto de ter vivido e crescido em Cali, na Colômbia, um país com numerosos, complexos e difíceis conflitos, contribuiu para uma certa perspectiva, uma motivação, talvez, uma necessidade de explorar isto até certo ponto no meu trabalho. Porém, sempre considerei que uma obra de arte requer desenvolvimento e não pode ser sustentada apenas por isto. O desenvolvimento desta realidade, destas experiências, elevando-as a um nível poético, a um nível universal e a um nível que se relaciona com a linguagem artística, é mais ou menos o que venho a explorar no meu trabalho. (Muñoz in AA.VV., 2009: 155-156)

Em “Aliento" (1995-2002), Muñoz apresenta um conjunto de espelhos circulares, aparentemente vazios. Porém quando o público se debruça sobre eles, para além de encontrar a sua imagem reflectida, descobre, respirando e assim embaciando o espelho, que uma outra imagem surge: num momento fugaz a imagem efémera de uma fotografia (retirada de um obituário de um jornal colombiano) toma o lugar do observador espelhado. $\mathrm{O}$ artista cria deste modo uma relação de dependência entre a vontade de lembrar os mortos, na acção de expirar e necessidade de continuar a viver, na acção de inspirar - sendo que no espelho, retratado e observador nunca podem existir em simultâneo. (Rocha, 2016)

Esta imagem escondida no espelho, latente como muitas memórias, não pode ser fixada. Só o acto de respirar (de um outro que não o retratado morto), ou de lhe soprar vida, a torna visível. Isto obriga o observador a manter uma dinâmica infrutífera de alternância entre a sua imagem e a imagem do retratado, numa tentativa desesperada de manutenção de uma imagem, de uma memória, em última análise de um indivíduo (metaforizado), que não pode em circunstância alguma durar. (Rocha, 2016)

Esta atitude sisífica repete-se na obra "Projecto para um Memorial"(2004-2005), mas desta vez encabeçada pelo artista. Na Bienal de Veneza de 2007, Óscar Muñoz apresentou esta obra, composta por cinco ecrãs mostrando uma mão que desenha um rosto atrás de outro, com um pincel molhado em água, sobre uma superfície de pedra cinzenta e quente, das ruas de Cali (cidade Columbiana). Terminado o desenho, a água começa a evaporar e o rosto desaparece gradualmente, até nada restar. Começa de seguida o desenho de uma nova face, igualmente destinada a desaparecer.

São, uma vez mais, rostos de pessoas desaparecidas nos conflitos armados na Colômbia; poderiam ser os desaparecidos ou os mortos de qualquer guerra em qualquer lugar. São retratos frontais, como em documentos de identificação, como se essa fosse a derradeira forma de reconhecimento possível perante os sistemas governamentais, que se revelam incapazes de minimizar as mortes em conflitos sociais, e de lembrar as memórias dos participantes da nossa história. 


\section{Práticas artísticas contra o esquecimento dos conflitos quotidianos na América LATINA}

Mais que criar distinções com base na dicotomia eixo europeu/norte-americano vs eixo latino-americano, sublinha-se através da breve apresentação destes três percursos o forte carácter independente e contestatário da obra de alguns artistas latino-americanos, que fazem do seu trabalho uma forma de luta social contra os problemas quotidianos dos seus países.

Tentar caracterizar o vasto espectro de práticas artísticas na América Latina, é um trabalho inglório, infrutífero e desadequado que conduziria sempre, como vimos, a muitas generalizações indesejadas, sobretudo se partirmos de uma posição comparativa. Não é esse portanto o objectivo deste texto. Reale, Margolles e Muñoz, não poderiam ser exemplos suficientes para caracterizar a diversidade de práticas artísticas activas, de artistas oriundos da América Latina. Porém, são exemplos incontornáveis e provatórios de práticas que, orbitando em torno do contexto de um lugar, o transcendem e se globalizam não só pela sua qualidade como pela pertinência dos seus questionamentos.

Regressando a Gerardo Mosquera, este argumenta que apesar da globalização da arte, há ainda a necessidade de referência a local de origem dos artistas, como forma de caracterização (Mosquera, 2010), como é possível ver, por exemplo, neste próprio texto - ainda que tal não seja feito de modo depreciativo. $\mathrm{Na}$ verdade, essa opção possui considerável legitimidade, como o próprio autor reconhece, concedida por alguns factos que estão muito para lá de uma motivação ou um sentido redutor: "não significa que não possam reconhecer-se certos rasgos comuns a alguns países ou áreas. $\mathrm{O}$ crucial é que estas identidades comecem a manifestar-se mais pelos suas características enquanto prática artística do que pelo uso de elementos significativos tomados do folclore, da religião do ambiente físico ou da história." (Mosquera, 2010:19)

Como característica de produção, unificadora destes três dispares artistas mencionados, parece haver uma preocupação acentuada que se manifesta sob a forma de um sentido activismo social como através da necessidade de manter a memória viva. Esta não é uma questão que possa ser pensada enquanto especifica ou transversal aos artistas oriundos da América Latina, porém arrisco dizer que é uma postura que se vinca com maior firmeza nestes, do que na maioria dos artistas oriundos do contexto europeu/norte-americano. Muito mais que qualquer folclore, nacionalismo ou regionalismo, parece ser justo destacar a arte contemporânea produzida por muitos artistas na América Latina como superior no seu envolvimento com o presente colectivo, e não com o passado.

No contexto europeu, as gerações mais recentes, cresceram num clima de segurança e paz, que tomam como duradouro dentro do perímetro do seu território, onde o impacto dos problemas sociais, das crises económicas, ou até mesmo do terrorismo, apesar de sentido é sublimado por uma qualidade de vida considerável e acessível à maioria da população. A este privilégio soma-se a noção genérica de eficácia dos sistemas de justiça e de ordem pública, bem como o apoio social dos estados que, apesar das suas imperfeições desempenha um papel relevante. Em suma, desde o final da II Guerra Mundial, que a maioria da Europa experimenta um ambiente de paz e relativa estabilidade (mesmo em momentos de evidente crise económica que implica grandes taxas de desemprego, como é o caso actual), o que num contexto global se revela um caso de excepção. 
Contudo, se reflectirmos sobre arte contemporânea, europeia mas também americana (onde o período de conflito se estendeu pela Guerra Fria, e que ainda hoje é um país envolvido em diferentes guerras, para lá das suas fronteiras - o que é fulcral), deparamo-nos com um panorama onde a morte, o trauma, a agressividade, a entropia e a disrupção, compõem fortes traços de orientação conceptual de obras que, por sua vez, se materializam numa estética alinhada com este perfil.

Há na arte contemporânea europeia/norte-americana uma necessidade de expiação colectiva por eventos passados (para além de uma dor psíquica individual que transparece na obra de numeroso artistas), que nas palavras de Donald Kuspit, se pode caracterizar do seguinte modo: "(...) o estilo moderno é um reino de actos falhados, um espaço íntimo onde o que é inconsciente se torna consciente como sintoma - um sinal obscuro mas revelador." (Kuspit 1995: 163). ${ }^{4}$ A arte contemporânea "(...) pode não ser auto-consciente sobre a morte, e como tal pode ter uma noção incompleta do eu, mas o pensamento da sua própria mortalidade aparece repetidamente na sua maneira desequilibrada, no seu fascínio com a incongruência, ambivalência, e ironia." (Kuspit 1995: 166)

Parece haver, aqui mais um sentido terapêutico (à falta de melhor expressão) relativo aos dramas da condição humana, do que um sentido de denúncia ou de combate social activo onde impere a expectativa de mudança (apesar do risco que esta generalização comporta).

$\mathrm{Na}$ América Latina, onde a corrupção, a violência, a instabilidade social, a discriminação e a falta de sistemas de apoio a grupos carenciados é uma realidade gritante, a arte parece reflectir muito mais o drama e a urgência do presente do que o trauma do passado. Fá-lo sem qualquer estratégia derivativa, apropriadora, ou submissa à ideia de vanguarda. Simplesmente é parte da arte contemporânea, em pleno direito, emancipada de avaliações simplificadoras. Apresentase conceptualmente independente, com uma poética que lhe é própria, deixando para trás o que Mosquera designou de neurose de identidade (Mosquera, 1996: 7). A arte da América Latina deixou de sê-lo, para dar lugar meramente a uma arte feita a partir da América Latina (Mosquera, 1996: 7-10).

Longe ficou a ideia de tropicalismo, de paraíso perdido. A não ser que a queiramos pensar como Oiticia: "O mito da tropicalidade é muito mais que araras e bananeiras: é a consciência de um não condicionamento às estruturas estabelecidas.” (Oiticica, 1968) E neste aspecto podemos encontrar, (porque como até Mosquera reconheceu, tendemos sempre a fazê-lo) um arquétipo da arte latino-americana que se foi concretizando e ganhando força: uma arte baseada numa consciência de um não condicionamento às estruturas estabelecidas.

O antropólogo brasileiro Eduardo Viveiros de Castro proporia, nesta linha, o conceito de "perspectivismo" para designar a forma de avaliar o mundo e de se relacionar com ele, própria das comunidades índias da amazónia: "Perspectivas não constituem representações (visuais ou de outro tipo) de objectos por sujeitos, mas relações de sujeitos com sujeitos" (Viveiros de Castro, 1998: 77). É natural relacionar esta afirmação com o trabalho, por exemplo, de artistas como Lygia Clark que pretendia impedir que as suas obras se tornassem objectos de consumo passivo, preferindo pensá-las como vivências. Ajuda-nos também a compreender que, se há uma

4 Todas as traduções presentes neste texto são realizadas pela sua autora. 
característica diferenciadora nas obras de artistas latino-americanos, como o inconformismo que sugeri, é uma que tem raiz, no limite, num conceito interno.

Vê-mo-la nos artistas referidos que, independentemente de uma postura política ou apolítica, não ignoram a realidade humana do contexto em que se encontram, sendo-lhes natural usar a arte como um modo de luta social, tentando mudar os dramas do presente, dialogando para lá de fronteiras, tendo o sujeito como interesse central.

Vimos que para Berna Reale é o silêncio de vítimas, agressores, testemunhas e cúmplices que constrói uma estrutura impenetrável de poder abusivo, tanto social, como institucional. O seu trabalho torna-se assim, por oposição, uma denúncia sistemática dos comportamentos humanos.

Para Berna, não esquecer a violência quotidiana é torná-la evidente. É colocá-la sempre sob o olhar de todos os que com ela, consciente ou inconscientemente compactuam. É perturbar o nosso bem-estar, a nossa acomodação, e exigir uma resposta.

Por outro lado, chocando, mas de modo indirecto, exigindo a atenção do observador, Teresa Margolles, puxa-nos o tapete debaixo dos pés, assim que tentamos descobrir o significado aparentemente hermético das peças ou das instalações que constrói.

A violência não é atirada para o nosso campo de visão. Somos nós, estimulados pela obra, que descobrimos a dureza do que através dela é comunicado. É nossa a responsabilidade de queremos saber; de desempenharmos uma postura activa, na qual a obra de Margolles verdadeiramente se concretiza. Ou então, simplesmente ignorarmos o pressentimento de morte que as suas obras emanam, e continuarmos alheados ao que nos circunda, seja a realidade da morte (em "Vaporización"), sejam os tormentos para quem sobrevive (subentendidos em "Entierro").

Margolles recorda-nos o drama dos conflitos sociais da América Latina, fazendo com que as suas evidências se infiltrem em nós, se tornem parte de nós e sejam, queiramos ou não, (metaforicamente) carregadas por nós; a artista perturba-nos emocionalmente, induzindo um sentimento de inquietude e ansiedade perante as suas obras, e esperando com isso, deixar-nos marcas reais e duradouras, no que respeita à nossa percepção do mundo.

Numa relação sofisticada entre visualidade e memória, para Oscar Muñoz, tudo o que não é visto é esquecido. A estética por si criada remete para a transitoriedade da imagem que retemos de acontecimentos e pessoas, sendo que o cerne da sua preocupação está em manter a memória da existência de vítimas.

Embora saibamos que os retratados por Muñoz, são indivíduos reais, cuja imagem é resgatada de antigos obituários, podemos aceitar que há na sua representação uma abordagem que nos permite uma identificação com qualquer contexto social: há uma universalização dos rostos que aumenta o nosso grau de empatia, pois preenchemos os traços fisionómicos em falta com as nossas próprias memórias.

A abordagem de Muñoz à condição precária da memória humana, e a sua constante tentativa em resgatá-la, não só para evitar o esquecimento das vítimas, mas sobretudo para evitar o esquecimento da vida que elas viveram, é, por si só, um condigno memorial à condição humana. 
Em suma, nestes três projectos artísticos, tão distintos, mas simultaneamente consonantes, permanece a ideia de que a arte pode fazer a diferença frente ao conflito. Não por ser pacificadora, não por acalmar consciências ou tranquilizar ansiedades, mas por mostrar que para mudar o mundo, é preciso conhecê-lo e mostrá-lo como ele é. É preciso pensar o sujeito, talvez mais que o objecto. Faz assim sentido relembrar a máxima de 1928, de Oswald de Andrade, presente no inicio deste texto, e que na verdade parece acompanhá-lo na totalidade: "Da adversidade vivemos!". Parecendo manter-se verdadeiro para os artistas contemporâneos que trabalham a partir da América Latina, arriscaria acrescentar que, no que concerne à qualidade artística: "Na adversidade prosperam(os)."

\section{REFERÊNCIAS}

AA.VV. 2009. Oscar Muñoz: Documentos de la amenesia. Badajoz: Museo Estremeño e Iberoamericano de Arte Contemporàneo.

Adorno, Theodor. 2005. Minima Moralia: Reflections on a Damaged Life. Londres: Verso.

Andrade, Oswald. 1928. Manifesto Antropófago. (http://enciclopedia.itaucultural.org.br/ obra35538/manifesto-antropofago)

Fonseca, Raphael. 2013. Entrevista com Berna Reale. Das Artes No30. Rio de Janeiro: Dasartes. (http:// http://dasartes.com/2012/entrevista-com-berna-reale-para-dasartes-n30-na-integra/)

Görner, Klause e Udo Kittelman. 2004. Teresa Margolles: Muerte sin Fin. Frankfurt: Museum für Moderne Kunst.

Kuspit, Donald. 1995. Signs of Psyche in Modern and Post-Modern Art. Nova Iorque: Cambridge University Press.

Molina, Camila. 2015. Berna Reale fala do tema da violência em suas obras para o $34^{\circ}$ Panorama do MAM. Estadão: Cultura Artes São Paulo. (http://cultura.estadao.com.br/noticias/artes,berna-reale-fala-do-tema-da-violencia-em-suas-obras-para-o-34o-panorama-do-mam,1778399)

Mosquera, Gerardo. 1996. El arte latinoamericano déjà de serlo. Madrid: ARCO Latino. . 2010. "Against Latin American Art” em Contemporary Art in Latin America, ed. Phoebe Adler, Tom Howells e Nikolaos Kotsopoulos. Londres: Black Dog Publishing.

Oiticica, Hélio. 1967. Esquema geral da Nova Objectividade. (http://tropicalia.com.br/leituras-complementares/esquema-geral-da-nova-objetividade) 1968. Tropicália. (http://tropicalia.com.br/leituras-complementares/tropicalia-3)

Rocha, Susana. 2014. "Berna Reale: A importância do choque e do silêncio na performance" em Estúdio 9, ed. João Paulo Queiroz. Lisboa: CIEBA-FBAUL. 2016. "Oscar Muñoz: paradoxos de uma estética do esquecimento" em Gama 7, ed. João Paulo Queiroz. Lisboa: CIEBA-FBAUL

Viveiros de Castro, Eduardo. 1998. Cosmological Perspectivism in Amazonia and Elsewhere. Londres: Cambridge University Press. 


\section{Artistic practices against the oblivion of eVeryday conflicts in Latin America: Berna Reale, Teresa Margolles and Oscar Muñoz}

Demystifying the vision of Latin American art as a minor art, dependent on the appropriation and reformulation of concepts imported from foreign universes, this article analyzes how the social context of a significant number of Latin American countries, and art's ability to intervene in the public sphere, has been crucial for the definitive affirmation of a legitimate autonomy that refuses any dependence from European and North American artistic praxis. Based on texts of the theorist Geardo Mosquera, and addressing the work of three contemporary Latin American artists - Berna Reale (Brazil), Teresa Margolles (Mexico) and Oscar Muñoz (Colombia) — it is made evident how Latin American arts, although socially involved with its context, presents themselves as global, surpassing any notion of frontier, participating in an international dialogue. It is suggested that if there is any characteristic that distinguishes Latin American arts, it is the artists' awareness of their independence of established structures.

Keywords: artistic practices, denouncement, Berna Reale, Teresa Margolles, Oscar Muñoz

Recebido em: 2016-11-30

Aceitado em: 2017-05-05 